\title{
Metabolic dysregulation in early onset psychiatric disorder before and after exposure to antipsychotic drugs
}

\author{
Rehmat Shah ${ }^{1,2 *}$, Fazal Subhan 1 , Syed Muhammad Sultan ${ }^{3}$, Matiul Haq ${ }^{4}$, Hussain Ahmad ${ }^{5}$, \\ Qasim Riaz Khan ${ }^{3}$, Gowhar Ali ${ }^{1}$, Sami Ullah ${ }^{1}$, Ihsan Ullah ${ }^{6 *}$
}

\begin{abstract}
${ }^{1}$ Department of Pharmacy, University of Peshawar, Peshawar, Khyber Pakhtunkhwa, Pakistan, ${ }^{2}$ Health Department, Peshawar, Khyber Pakhtunkhwa, Pakistan, ${ }^{3}$ Department of Psychiatry, Medical Teaching Institution, Khyber Medical College/Khyber Teaching Hospital Peshawar, Khyber Pakhtunkhwa, Pakistan, ${ }^{4}$ Radioimmunoassay Laboratory, Institute of Radiotherapy and Nuclear Medicine, Peshawar, Khyber Pakhtunkhwa, Pakistan, ${ }^{5}$ Medical teaching institution, District headquarter Hospital,

Dera Ismail Khan, ${ }^{6}$ Department of Pharmacy, University of Swabi, Swabi, Khyber Pakhtunkhwa, Pakistan
\end{abstract}

\begin{abstract}
Antipsychotic Drugs (APDs) are being widely prescribed to treat various disorders, including schizophrenia and bipolar disorder; however, abnormal glucose metabolism and weight gain have been reported with Atypical Anti-Psychotic drugs (AAPDs) that can lead to insulin-resistance and type 2 diabetes mellitus. The study was designed to assess various biochemical parameters including insulin and blood sugar before and after exposure to APDs in order to exclude the involvement of psychiatric disorders and certain other factors in metabolic dysregulations. Fifty seven APDs-naïve patients with first episode psychosis were divided into six groups who received olanzapine, quetiapine, risperidone, aripiprazole, haloperidol or combination of olanzapine with escitalopram and haloperidol. The serum samples were taken before the intake of the first dose and then on follow-up. Decrease in the level of elevated insulin and glucose was observed post-treatment in some patients, while others were observed whose insulin and glucose levels increased post-treatment, yet some patients did not show any disturbance in the insulin and glucose levels. It is concluded that psychiatric disorders by itself, narcotics, cigarette smoking and use of oral snuff may be also be implicated in metabolic dysregulations. The effects of APDs on insulin and glucose in healthy volunteers might be different than in patients with psychiatric disorders.
\end{abstract}

Keywords: Olanzapine. Quetiapine. Risperidone. Antipsychotics. Pancreas. Insulin.

\section{INTRODUCTION}

Psychosis is a broad term that relates to a person not in touch with reality. as patient cannot distinguish between factual and fictional. Psychotic disorders involve striking disturbances of thought, perception, affect, and behavior (Pantelis et al., 2003). The mortality rate is two or three times more in psychotic patients especially schizophrenics than in general population. The antipsychotic drugs have been documented as a considerable cause of excess mortality rate in psychotic patients (Mitchell, Lord, 2010; Vancampfort et al., 2013). Atypical Antipsychotic Drugs (AAPDs) have been widely prescribed to treat psychosis

\footnotetext{
* Correspondence: R. Shah. Department of Pharmacy, University of Peshawar, Peshawar, Pakistan. Tel:+92 091 9216750; Cell: +92 3459824130; Fax: +92-91921813. E-mail: rehmatshah@upesh.edu.pk \& Ihsan Ullah, Department of Pharmacy, University of Swabi, Swabi, Khyber Pakhtunkhwa, Pakistan. Cell: +92 3339878224 Email: Ihsanmkd@gmail.com, Ihsanmkd@uoswabi.edu.pk iD
}

and various other disorders, including schizophrenia and bipolar disorders. However, hyperglycemia and weight gain are reported with AAPDs (clozapine, olanzapine, quetiapine, risperidone and aripiprazole) that can lead to insulin-resistance and type 2 diabetes mellitus (Baptista, Parada, Hernandez, 1987). It is still controversial whether the metabolic abnormalities are associated with the psychiatric disorder(s) or the antipsychotic drugs (AAPDs) (Ballon et al., 2014; Baptista, Parada, Hernandez, 1987; Cope et al., 2005; Goldstein, 1999). Several studies have correlated weight gain with AAPDs by different mechanisms including orexigenic effect (hence larger food intake) and histamine $\mathrm{H}_{1}$ receptors antagonism (Ballon et al., 2014). AAPDs have been frequently reported to cause hyperglycemia, both in animals (Baptista, Parada, Hernadez, 1987) and humans (Bergman, Ader, 2005). Several mechanisms of AAPDs to disturb glucose homeostasis have been hypothesized including blockade of 
$\mathrm{M}_{3}$ receptors on beta cells of the pancreas (Weston-Green, Huang, Deng, 2011), weight gain and adiposity (Gohlke et al., 2012), damage of beta cells (Chiu et al., 2006; Shah et al., 2015) and tissue resistance to insulin (Ebenbichler et al., 2003). We have previously reported damage of pancreatic beta cells and rise in blood sugar with chronic olanzapine treatment, the later was observed in $8^{\text {th }}$ week of a 14 weeks once daily dosing in male rats, but weight loss instead of gain was observed, perhaps due to use of male gender and restricted access to food (Shah et al., 2015). There are studies which have reported hyperinsulinemia in medicated schizophrenics (Weston-Green, Huang, Deng, 2013). Chiu and his colleagues have reported no change in the levels of fasting glucose and glucose stimulated fasting insulin in patients treated with olanzapine and risperidone for two weeks, however, insulin level was decreased in olanzapine group after two weeks (Chiu et al., 2006), which has been hypothesized to be due to impairment of pancreatic beta cell function. They have also reported hypoinsulinemia in a cohort of Taiwanese schizophrenics following first 2 weeks treatment with olanzapine which returned to baseline by 4 weeks and hyperinsulinemia by 8 weeks (Chiu et al., 2010). There are apparent contrasts in reports about effects of AAPDs on insulin release (Weston-Green, Huang, Deng, 2013), perhaps due to difference in settings of the study, models being used and drug selected. Genetic variation and predisposing risks for diabetes are also important to be considered rather antipsychotic drugs only.

Different techniques have been used to assess the concentration of insulin and/or c-peptide including hyperglycemic clamp and oral glucose tolerance tests (Manu et al., 2013; Meier et al., 2001; Newcomer et al., 2002). The results are contrary whether AAPDs cause damage to beta cells (Newcomer et al., 2002; Shah et al., 2015), hyperinsulinemia (Manu et al., 2013; WestonGreen, Huang, Deng, 2013) or the hypothesis that AAPDs particularly olanzapine and risperidone directly impair pancreatic cell function is incorrect (Sowell et al., 2002). We have already hypothesized in our previous study and there are reports that these metabolic abnormalities might be due to schizophrenia itself and other risk factors rather the AAPDs since schizophrenics are usually underweight with poor pulse control, low blood pressure, tachycardia and deranged lipid profile (Shah et al., 2015).

AAPDs might cause abnormalities in lipid metabolism via both obesity-related and obesity-urelated molecular pathways, but no attention has been paid to the assessment of even most easily measurable metabolic parameters (De Hert et al., 2012). These metabolic abnormalities including cardiovascular events have been correlated with weight gain induced by AAPDs, with the reports that clozapine and olanzapine have the greatest risk, risperidone and quetiapine with low to moderate risk while aripiprazole has the minimal potential risk of clinically significant weight gain. Asymptomatic elevation in liver enzymes have been reported with olanzapine, quetiapine, risperidone and certain other commonly used typical and atypical antipsychotic drugs (Garcia-Unzueta et al., 2003; McManus, 1999). Elevated cholesterol and triglycerides levels have been reported with antipsychotic drugs (APDs) (Lindenmayer et al., 2003; McIntyre, McCann, Kennedy, 2001) that could predispose patients to cardiovascular accidents. Neuroleptic Malignant Syndrome (NMS) has also been reported with AAPDs that is characterized by severe muscle rigidity, fever and elevation of CPK (Strawn et al., 2007). There are no reports on the effect of antipsychotic drugs on renal function in human.

The studies conducted so far in this context, report the effects of these drugs on some parameters while ignore the others. Results have been presented in parts which do not give proper picture of the mechanisms of APDs-induced toxicities. We therefore designed this study involving drug naïve schizophrenics/first episode psychotics to unveil the fact whether APDs are really responsible to cause metabolic abnormalities while assessing all of the related parameters

\section{METHODS AND MATERIAL}

\section{Subjects and procedures}

Antipsychotic drugs-naïve non-diabetic patients $(\mathrm{n}=57)$ with first episode psychosis admitted to psychiatry unit or who visited OPD, Medical Teaching Institution, Khyber Teaching Hospital, Peshawar, K.P, Pakistan or Sayed Psychiatry Clinic, Peshawar, were included in this study. Patients of either gender with no history of antipsychotics aging not less than 18 years were part of the study. The patients on olanzapine, quetiapine, risperidone, aripiprazole and haloperidol monotherapies were grouped as OLAN ( $n=8)$, QUET $(n=8), \operatorname{RISP}(n=8), \operatorname{ARIP}(n=8)$ and HAL $(n=8)$ respectively while patients receiving combination of olanzapine with escitalopram, diazepam (STAT, I.V), and haloperidol (STAT, I.M) were grouped as OLEDH $(n=8)$. Six patients failed to report for follow-up and three were dropped due to non-compliance. The patients were followed for an average time period of 39 days for OLEDH, 40 days for QUET, 45 days for OLAN, 38 days for RISP, 30 days for ARIP and 33 days for haloperidol.

All subjects gave written informed consent otherwise excluded from the study. Pregnant females, obese and those with complicating pathologies including diabetes, 
and those with hepatic and renal impairment were not included in the study.

The patients were interviewed by consultants or medical officers to assess their mental state for differential diagnosis. Positive and negative syndrome scale (PANSS) and ICD-10 criteria were applied for proper diagnosis before the commencement of treatment. Drugs were chosen on the basis of patient condition, severity of the disease and age.

All procedures were approved by the Ethical Committee of the Department of Pharmacy, University of Peshawar (Reference number, 02/EC-14/Pharm)) and that of the Khyber Medical College/Khyber Teaching Hospital/ Khyber College of Dentistry, Peshawar (No-49/MBW/ KTH, dt. 30/10/2013).

\section{Laboratory and clinical measurements}

\section{Body weight and random blood glucose}

Random blood glucose (RBG) and body weight were assessed at the time of the first recruitment to study and then on follow-up visit. Abbott glucometer was used for blood glucose measurements before and after the treatment. The random glucose level more than $140 \mathrm{mg} /$ dl was considered disturbed glucose level.

\section{Insulin and c-Peptide}

Blood samples were taken before the administration of the first dose of the selected drug and then on follow-up. The blood samples were centrifuged and the isolated serum samples were stored at $-20{ }^{\circ} \mathrm{C}$ till analyzed for insulin and c-Peptide, at the Radioimmunoassay Laboratory (RIA), Institute of Radiotherapy and Nuclear Medicine (IRNUM), Peshawar. Insulin and c-Peptide IRMA Kits (Lot \#. 150525-C) were purchased from Beckman Coulter, Czech Republic. The level greater than $26.5 \mu \mathrm{IU} / \mathrm{mL}$ was considered abnormal.

Procedure for assessment of insulin and c-peptide levels

All the reagents were allowed to stay at room temperature. The content of the vial (control) was reconstituted with distilled water, after 10 minutes gentle mixing was performed to avoid foaming. Wash solution was prepared by pouring the content of the vial into $950 \mathrm{ml}$ of distilled water followed by homogenization. Precipitation reagent was taken in a volume of $400 \mu \mathrm{L}$ and added to $400 \mu \mathrm{L}$ of control as well as unknown sample in a glass tube. The contents were shaken using vortex mixer followed by centrifugation for 15 minutes at $3000 \mathrm{~g}$ and $4{ }^{\circ} \mathrm{C}$.
Results were obtained by planting the tubes containing prepared solution in specialized sample cuvettes of the IRMA analyzer.

Assessment of\% beta cells function (Matthews et al., 1985)

The function of the pancreatic beta cells was assessed using the following formula.

Beta cell function $(\%)=20 \mathrm{x}$ insulin/glucose -3.5

Assessment of insulin resistance (IR) (Matthews et al., 1985)

Insulin resistance (near approximation) was measured by using the following formula.

Insulin resistance $(I R)=$ insulin $x$ glucose $/ 22.5$

\section{Other biochemistry}

Serum ALT, AST, amylase, lipase, cholesterol, triglycerides, blood urea, serum creatinine and CPK were assessed at Pakistan Health Research Council (PHRC), Khyber Medical College (KMC), Peshawar, using Microlab 300 (Merck, Germany).

\section{STATISTICAL ANALYSIS}

Analysis of Variance (ANOVA), Bonferroni's multiple comparison test was used to determine differences among groups (Level of significance, $\mathrm{P} \leq 0.05$ ). Data were expressed as mean \pm standard error of mean (SEM). Graph Pad Prism 5 (Graph Pad Software Inc. San Diego CA, USA) was used as a statistical tool of analysis.

\section{RESULTS}

\section{Body weight and random blood glucose (RBG)}

No significant gain in random blood glucose (Figure 1) and body weight (Figure 2) $(\mathrm{P}>0.05)$ was noticed in all patients during their treatment tenure.

However, $14.03 \%$ of the total population showed elevated random blood glucose (RBG) before antipsychotics exposure. Among the addicted population, $38.46 \%(5 / 13$ patients) with addiction of cannabis/charas, $40 \%(2 / 5$ patients) with habit of smoking tobacco and $41.67 \%$ (5/12 patients) with the habit of using oral snuff (Naswar) were presented with abnormally elevated RBG levels before exposure to APD(s). Interestingly, the level of RBS decreased from abnormal to normal in $10.53 \%$ of the total population, but elevated from normal to abnormal in $8.77 \%$ of the total population. Out of the non-addicted population 
(27/57), 22.22\% (6/27 patients) were found with elevated blood sugar. Only, $12.5 \%$ (1/8 patients) of the combination, QUET and RISP groups, $25 \%$ (2/8 patients) of the OLAN and ARIP groups and $0 \%(0 / 8$ patients) of the HAL group were shown with elevated RBS levels (Table I).

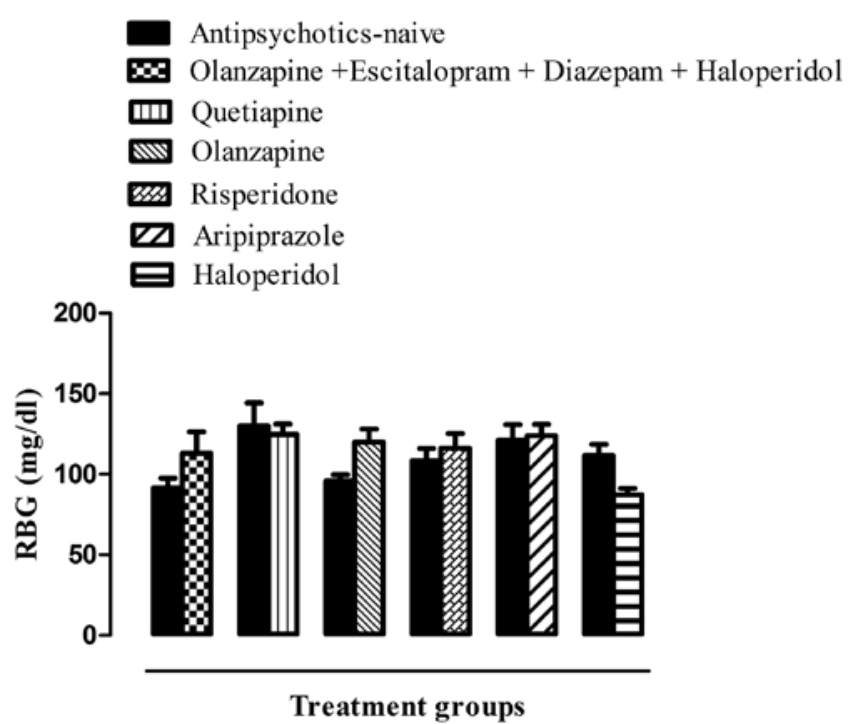

FIGURE 1 - Effect of selected antipsychotics on random blood glucose: Antipsychotic-naïve patients were put on olanzapine in combination with escitalopram, diazepam (STAT, I.V) and haloperidol (STAT, I.M) (OLEDH, $n=8)$, quetiapine (QUET, $n=8$ ), olanzapine (OLAN, $n=8$ ), risperidone (RISP, $n=8$ ), aripiprazole $(n=8)$ or haloperidol $(n=8)$ in therapeutic doses for an average time period of $39,40,45,38,30$ and 33 days respectively showing no significant change in random blood glucose as compared to antipsychotics-naïve patients $(n=8)$ (ANOVA followed by Bonferroni’s Multiple Comparison Test) $(\mathrm{P}>0.05)$.

\section{Effect on the level of Insulin and c-peptide}

No statistically significant difference were observed in the level of insulin (Figure 3) and c-peptide (Figure 4) in drug treated groups compared to drug naïve patients

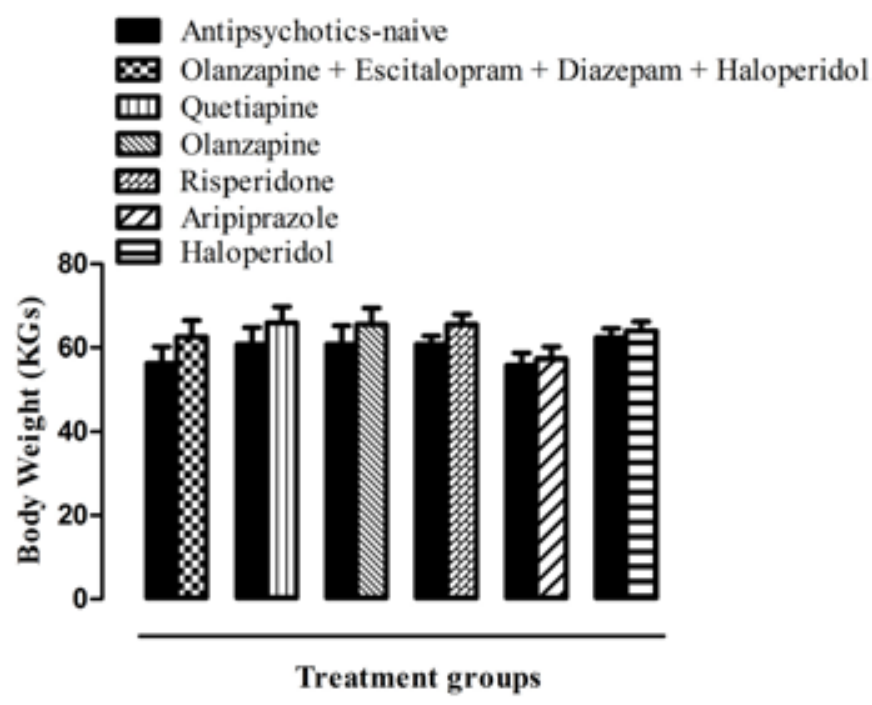

FIGURE 2 - Effect of selected antipsychotics on body weight: Antipsychotic-naïve patients were put on olanzapine in combination with escitalopram, diazepam (STAT, I.V) and haloperidol (STAT, I.M) (OLEDH, $\mathrm{n}=8$ ), quetiapine (QUET, $n=8)$, olanzapine (OLAN, $n=8)$, risperidone (RISP, $n=8$ ), aripiprazole $(n=8)$ or haloperidol $(n=8)$ in therapeutic doses for an average time period of $39,40,45,38,30$ and 33 days respectively showing no significant change in body weight as compared to antipsychotics-naïve patients $(n=8)$ (ANOVA followed by Bonferroni's Multiple Comparison Test) $(\mathrm{P}>0.05)$.

TABLE I - Per cent wise distribution of patients with disturbed ( $\geq 140 \mathrm{mg} / \mathrm{dl}$ ) glucose before and after exposure to antipsychotic treatment

\begin{tabular}{|c|c|c|c|c|c|c|c|}
\hline $\begin{array}{c}\text { DGBT } \\
\text { (Drug naïve } \\
\text { patients) }\end{array}$ & $\begin{array}{c}\text { DGAT } \\
\text { (OLEDH) }\end{array}$ & $\begin{array}{c}\text { DGAT } \\
\text { (QUET) }\end{array}$ & $\begin{array}{l}\text { DGAT } \\
\text { (OLAN) }\end{array}$ & $\begin{array}{l}\text { DGAT } \\
\text { (RISP) }\end{array}$ & $\begin{array}{l}\text { DGAT } \\
\text { (ARIP) }\end{array}$ & $\begin{array}{l}\text { DGAT } \\
\text { (HAL) }\end{array}$ & $\begin{array}{c}\text { DGAT } \\
\text { (All groups) }\end{array}$ \\
\hline $\begin{array}{c}14.03 \\
(\mathrm{n}=57)\end{array}$ & $\begin{array}{l}12.5 \% \\
(\mathrm{n}=8)\end{array}$ & $\begin{array}{l}12.5 \% \\
(\mathrm{n}=8)\end{array}$ & $\begin{array}{l}12.5 \% \\
(\mathrm{n}=8)\end{array}$ & $\begin{array}{l}12.5 \% \\
(\mathrm{n}=8)\end{array}$ & $\begin{array}{l}25 \% \\
(\mathrm{n}=8)\end{array}$ & $\begin{array}{c}0 \% \\
(\mathrm{n}=8)\end{array}$ & $\begin{array}{l}14.58 \% \\
(\mathrm{n}=48)\end{array}$ \\
\hline \multicolumn{6}{|c|}{ Level of RBG reduced with treatment (from abnormal to normal) } & $5 / 48$ & $10.42 \%$ \\
\hline \multicolumn{6}{|c|}{ Level of RBG elevated with treatment (from normal to abnormal) } & $6 / 48$ & $12.5 \%$ \\
\hline \multicolumn{6}{|c|}{ Patients abusing charas and cannabis presented with abnormal RBG levels (APDs-naive) } & $5 / 57$ & $8.77 \%$ \\
\hline \multicolumn{6}{|c|}{ Patients smoking tobacco presented with abnormal RBG levels (APDs-naive) } & $2 / 57$ & $3.51 \%$ \\
\hline \multicolumn{6}{|c|}{ Patients abusing oral snuff/naswar presented with abnormal RBG levels (APDs-naive) } & $5 / 57$ & $8.77 \%$ \\
\hline \multicolumn{6}{|c|}{ Total patients with any kind of drug dependence presented with elevated RBG (APDs-naive) } & $12 / 57$ & $40 \%$ \\
\hline
\end{tabular}

DGBT $=$ Deranged Glucose Before Treatment, DGAT = Deranged Glucose After Treatment, OLEDH= Group of patients who received olanzapine + Escitalopram i.v STAT + Diazepam i.v STAT + Haloperidol i.v STAT, QUET $=$ Group of patients who received quetiapine, OLAN $=$ Group of patients who received olanzapine, $\mathrm{RISP}=$ Group of Patients who received risperidone, $\mathrm{HAL}=$ Group of patients who received haloperidol, ARIP $=$ Group of patients who received aripiprazole. 
(ANOVA, $\mathrm{P}>0.05$ ).

However, it was observed that $21.05 \%$ of the total population presented abnormally elevated insulin levels when compared with reference. Similarly, $22.81 \%(13 / 57$ patients), $8.77 \%$ (5/57 patients), $21.05 \%$ (12/57) of the total population were found addicts of cannabis/charas, tobacco and oral snuff (Naswar) respectively. Thus $38.46 \%$ (5/13 patients) with addiction of cannabis/charas, $40 \%(2 / 5$ patients) with habit of smoking tobacco and $33.33 \%$ (4/12 patients) with the habit of using oral snuff (Naswar) were presented with abnormally elevated insulin levels. Ten patients were found whose level decreased from abnormal to normal after the commencement of APD treatment, but the same number of patients were found whose insulin level elevated from normal to abnormal with the APD treatment.

On the other hand, $40.74 \%$ (11/27 patients) of the non-addicts were shown with elevated insulin levels. Only $3.51 \%$ (2/8 patients), $7.02 \%$ (4/8 patients), $3.51 \%$ (2 patients), $0 \%$ (0/8 patients), $7.02 \%$ (4/8 patients) and $0 \%$ (0/8 patients) of the combination (OLEDH), quetiapine (QUET), olanzapine (OLAN), risperidone (RISP), aripiprazole (ARIP) and haloperidol (HAL) groups respectively showed elevated insulin levels before the commencement of respective treatment (Table II).

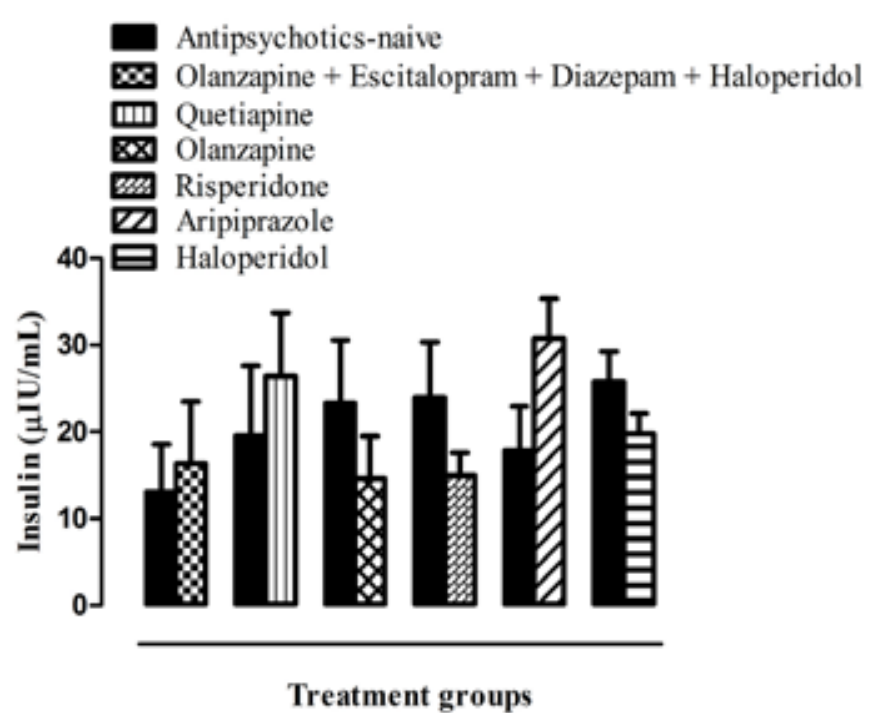

FIGURE 3 - Effect of selected antipsychotics on insulin: Antipsychotic-naïve patients were put on olanzapine in combination with esitalopram, diazepam (STAT, I.V) and haloperidol (STAT, I.M) (OLEDH, $\mathrm{n}=8$ ), quetiapine (QUET, $\mathrm{n}=8$ ), olanzapine (OLAN, $\mathrm{n}=8$ ), risperidone (RISP, $\mathrm{n}=8$ ), aripiprazole $(\mathrm{n}=8)$ or haloperidol $(\mathrm{n}=8)$ in therapeutic doses for an average time period of 39, 40, 45, 38, 30 and 33 days respectively showing no significant change in insulin as compared to antipsychotics-naïve patients (ANOVA followed by Bonferroni's Multiple Comparison Test $)(\mathrm{P}>0.05)$.
DIBT $=$ Deranged Insulin Before Treatment, DIAT $=$ Deranged Insulin After Treatment, OLEDH= Group of patients who received olanzapine + Escitalopram i.v STAT + Diazepam i.v STAT + Haloperidol i.v STAT, QUET= Group of patients who received quetiapine, OLAN = Group of patients who received olanzapine, RISP $=$ Group of Patients who received risperidone, HAL $=$ Group of patients who received haloperidol, ARIP $=$ Group of patients who received aripiprazole.

\section{Effect on beta cells function $(\% \beta)$ and insulin resistance (IR)}

beta cells function $(\% \beta)$ (Figure 5) and insulin resistance (IR) (Figure 6) of drug naïve patients was compared with that of olanzapine (OLAN, $n=8)$, quetiapine (QUET, $\mathrm{n}=8$ ), risperidone (RISP, $\mathrm{n}=8$ ), aripiprazole (ARIP, $n=8$ ), haloperidol (HAL, $n=8)$ and combination of olanzapine with escitalopram, diazepam (STAT, I.V) and haloperidol (STAT, I.M) (OLEDH, $n=8)$ which showed no significant change in the level of $\% \beta$ cell function and Insulin resistance (ANOVA followed by Bonferroni's Multiple Comparison Test) $(\mathrm{P}>0.05)$.

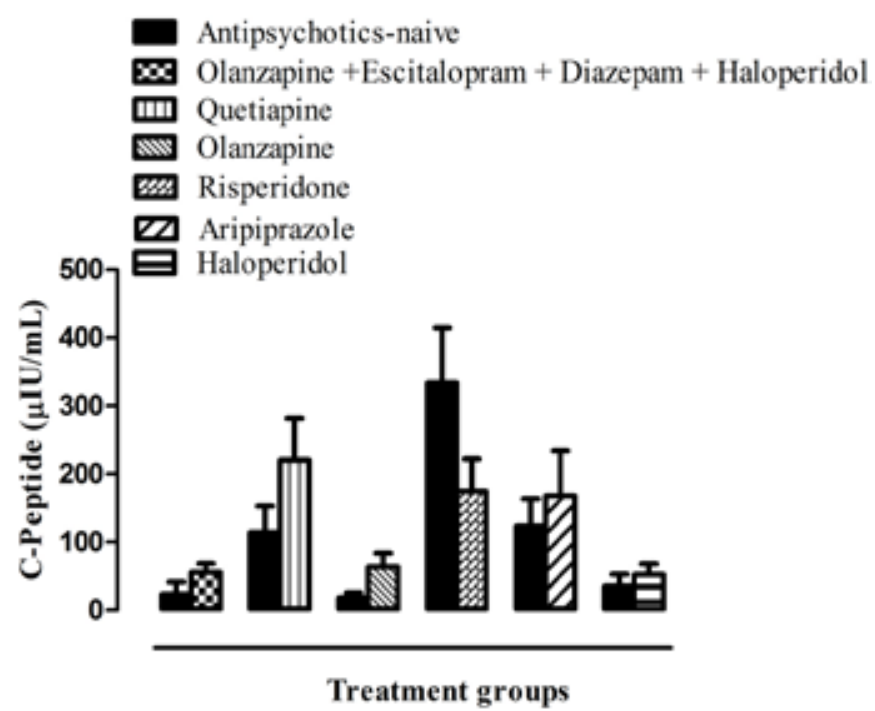

FIGURE 4 - Effect of selected antipsychotics on c-peptide: Antipsychotic-naïve patients were put on olanzapine in combination with esitalopram, diazepam (STAT, I.V) and haloperidol (STAT, I.M) (OLEDH, $\mathrm{n}=8$ ), quetiapine (QUET, $\mathrm{n}=8$ ), olanzapine (OLAN, $\mathrm{n}=8$ ), risperidone (RISP, $\mathrm{n}=8$ ), aripiprazole $(n=8)$ or haloperidol $(n=8)$ in therapeutic doses for an average time period of 39, 40, 45, 38, 30 and 33 days respectively showing no significant change in c-peptide as compared to antipsychotics-naïve patients (ANOVA followed by Bonferroni's Multiple Comparison Test $)(\mathrm{P}>0.05)$. 


\section{Effect on the level of cholesterol and triglycerides}

Significant elevation in the level of cholesterol was observed in aripiprazole treated group (ARIP, $n=8$,
${ }^{*} \mathrm{P}<0.05$ ) when compared to APDs-naive (Figure 7). No significance was noticed in the level of triglycerides in any of the treated groups (Figure 8$)(\mathrm{P}>0.05)$.

TABLE II - Per cent wise distribution of patients with disturbed ( $>26.5 \mu \mathrm{IU} / \mathrm{mL})$ insulin levels before and after exposure to antipsychotic treatment

\begin{tabular}{|c|c|c|c|c|c|c|c|}
\hline $\begin{array}{c}\text { DIBT } \\
\text { (APDs native } \\
\text { patients } \\
\end{array}$ & $\begin{array}{c}\text { DIAT } \\
\text { (OLEDH) }\end{array}$ & $\begin{array}{c}\text { DIAT } \\
\text { (QUET) }\end{array}$ & $\begin{array}{c}\text { DIAT } \\
\text { (OLAN) }\end{array}$ & $\begin{array}{c}\text { DIAT } \\
\text { (RISP) }\end{array}$ & $\begin{array}{l}\text { DIAT } \\
\text { (ARIP) }\end{array}$ & $\begin{array}{l}\text { DIAT } \\
\text { (HAL) }\end{array}$ & $\begin{array}{c}\text { DIAT } \\
\text { (All drugs) }\end{array}$ \\
\hline $\begin{array}{c}21.05 \% \\
(\mathrm{n}-57)\end{array}$ & $\begin{array}{c}3.51 \% \\
(\mathrm{n}=8)\end{array}$ & $\begin{array}{c}7.02 \% \\
(n=8)\end{array}$ & $\begin{array}{c}3.51 \% \\
(\mathrm{n}=8)\end{array}$ & $\begin{array}{c}0 \% \\
(\mathrm{n}=8)\end{array}$ & $\begin{array}{c}7.02 \% \\
(n=8)\end{array}$ & $\begin{array}{c}0 \% \\
(\mathrm{n}=8)\end{array}$ & $\begin{array}{c}21.05 \% \\
(\mathrm{n}=48) \\
\end{array}$ \\
\hline \multicolumn{6}{|c|}{ Insulin level reduced with treatment (From abnormal to normal) } & $10 / 48$ & $17.54 \%$ \\
\hline \multicolumn{6}{|c|}{ Insulin level increased with treatment (From normal to abnormal) } & $10 / 48$ & $17.54 \%$ \\
\hline \multicolumn{6}{|c|}{ Patients using cannabis and charas presented with DIBT } & $13 / 57$ & $22.81 \%$ \\
\hline \multicolumn{6}{|c|}{ Patients with smoking habits (tobacco) presented with DIBT } & $5 / 57$ & $8.77 \%$ \\
\hline \multicolumn{6}{|c|}{ Patients with addiction of Naswar/oral snuff presented with DIBT } & $12 / 57$ & $21.05 \%$ \\
\hline \multicolumn{6}{|c|}{ Total patients with any kind of addiction (Charas, smoking, naswar, cannabis) } & $30 / 57$ & $52.63 \%$ \\
\hline \multicolumn{6}{|c|}{ Patients without any addiction presented with DIBT } & $27 / 57$ & $47.37 \%$ \\
\hline
\end{tabular}

DIBT=Deranged Insulin Before Treatment, DIAT = Deranged Insulin After Treatment, OLEDH= Group of patients who received olanzapine + Escitalopram i.v STAT + Diazepam i.v STAT + Haloperidol i.v STAT, QUET = Group of patients who received quetiapine, $\mathrm{OLAN}=$ Group of patients who received olanzapine, $\mathrm{RISP}=$ Group of Patients who received risperidone, $\mathrm{HAL}=\mathrm{Group}$ of patients who received haloperidol, ARIP = Group of patients who received aripiprazole.

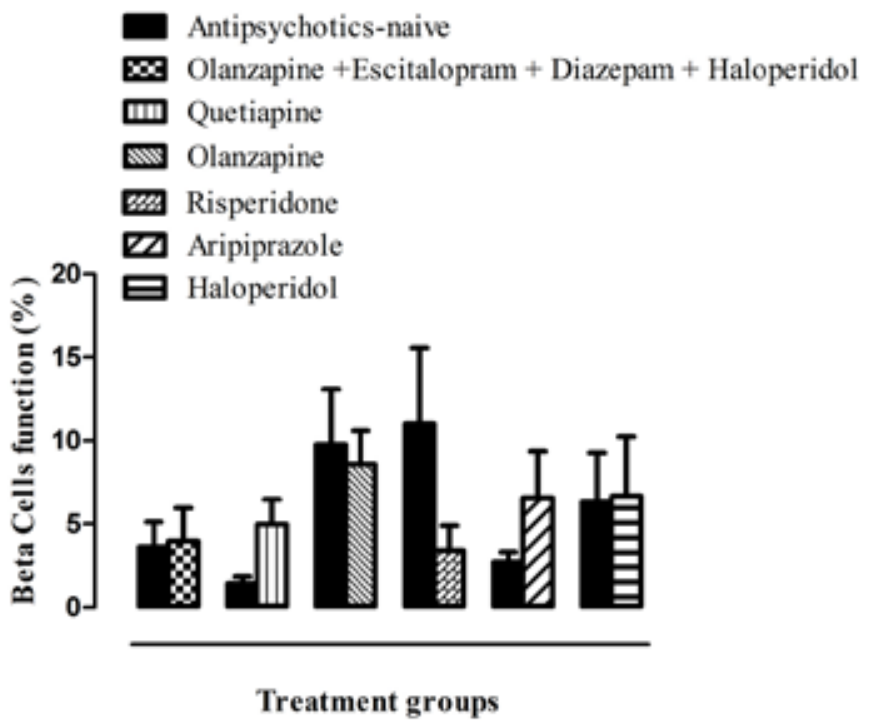

FIGURE 5 - Assessment of beta cells function $(\% \beta)$ : Antipsychotic-naïve patients were treated with olanzapine in combination with escitalopram, diazepam (STAT, I.V) and haloperidol (STAT, I.M) (OLEDH, $\mathrm{n}=8)$, quetiapine (QUET, $\mathrm{n}=8$ ), olanzapine (OLAN, $\mathrm{n}=8$ ), risperidone (RISP, $\mathrm{n}=8$ ), aripiprazole $(\mathrm{n}=8)$ or haloperidol $(\mathrm{n}=8)$ in therapeutic doses for an average time period of 39, 40, 45, 38, 30 and 33 days respectively showing no significant change in $\% \beta$ as compared to antipsychotics-naïve patients (ANOVA followed by Bonferroni's Multiple Comparison Test) $(\mathrm{P}>0.05)$.

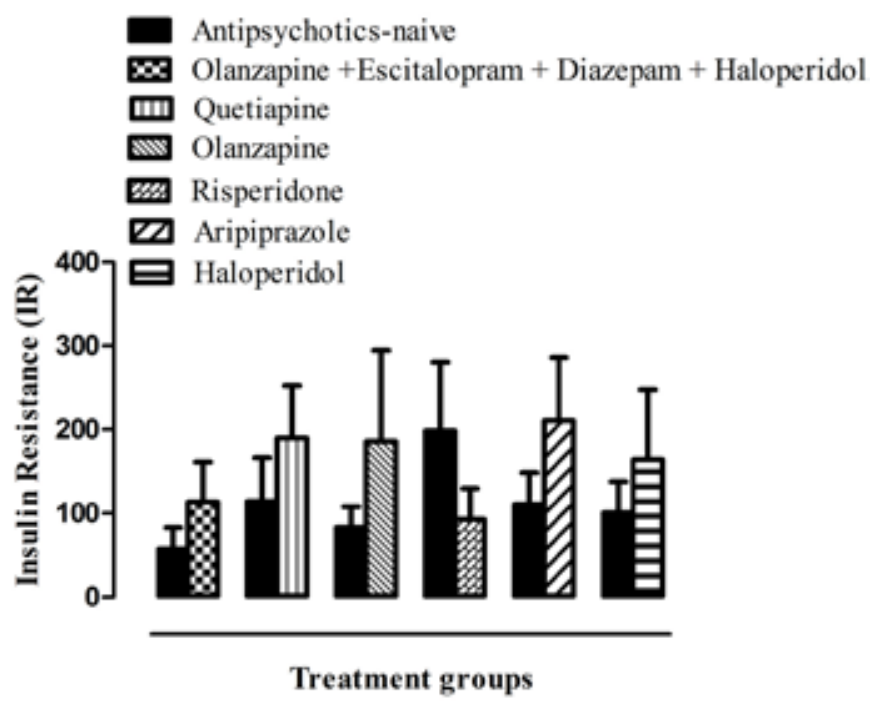

FIGURE 6 - Assessment of beta insulin resistance (IR): Antipsychotic-naïve patients were treated with olanzapine in combination with escitalopram, diazepam (STAT, I.V) and haloperidol (STAT, I.M) (OLEDH, $\mathrm{n}=8$ ), quetiapine (QUET, $\mathrm{n}=8$ ), olanzapine (OLAN, $\mathrm{n}=8$ ), risperidone (RISP, $\mathrm{n}=8$ ), aripiprazole $(\mathrm{n}=8)$ or haloperidol $(\mathrm{n}=8)$ in therapeutic doses for an average time period of 39, 40, 45, 38, 30 and 33 days respectively showing no significant change in IR as compared to antipsychotics-naive patients (ANOVA followed by Bonferroni's Multiple Comparison Test) $(\mathrm{P}>0.05)$. 


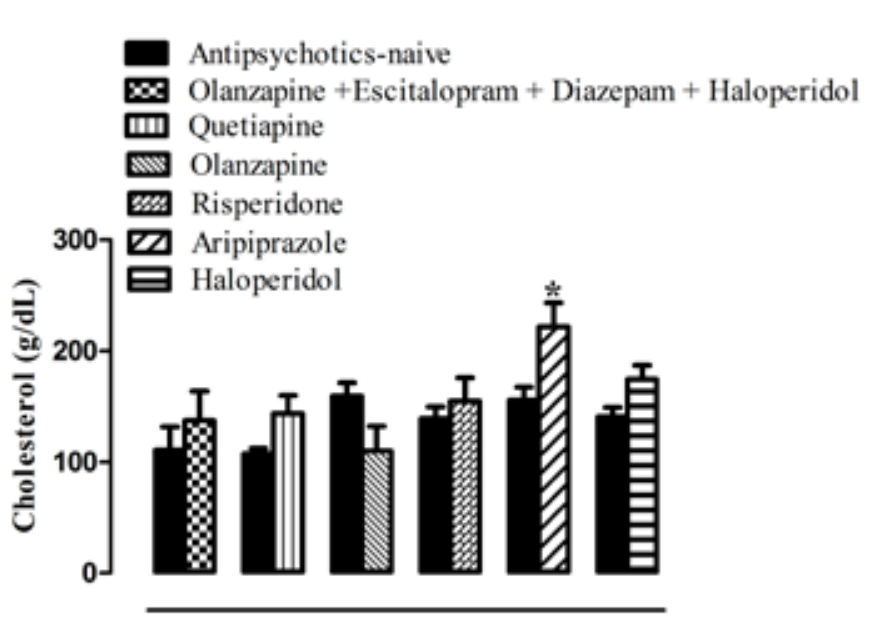

Treatment groups

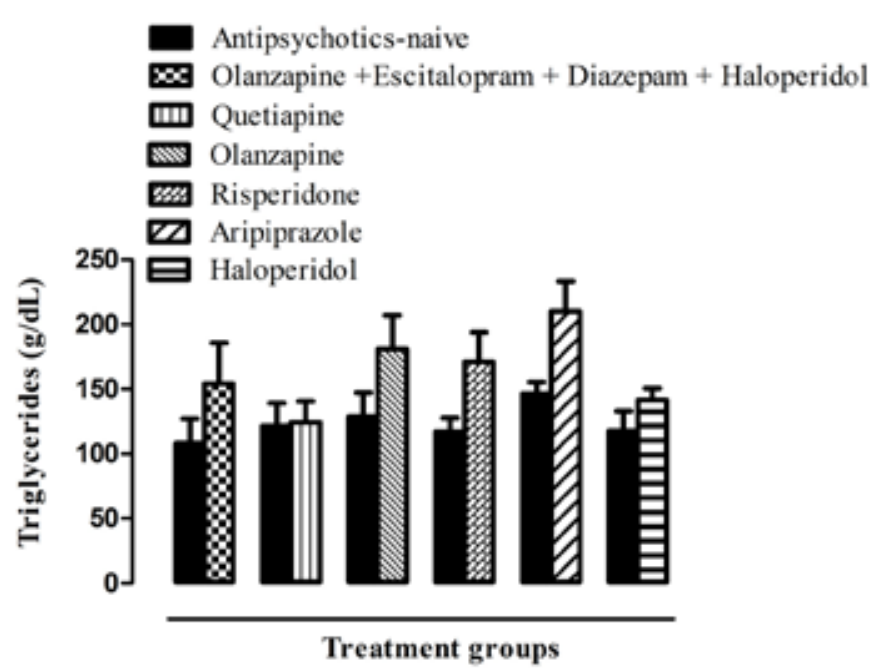

FIGURE 8 - Effect of selected antipsychotics on triglycerides (TGs): Antipsychotic-naïve patients were treated with olanzapine in combination with escitalopram, diazepam (STAT, I.V) and haloperidol (STAT, I.M) (OLEDH, $n=8)$, or quetiapine (QUET, $n=8)$, olanzapine (OLAN, $n=8)$, risperidone (RISP, $n=8)$, aripiprazole $(n=8)$ or haloperidol $(n=8)$ in therapeutic doses for an average time period of $39,40,45,38$, 30 and 33 days respectively showing no significant elevation in triglycerides as compared to antipsychotics-naive patients (ANOVA followed by Bonferroni's Multiple Comparison Test) $(* \mathrm{P}<0.05)$.

\section{DISCUSSION}

To evaluate changes in glucose homeostasis among APDs-naïve patients with first episode psychosis after use of olanzapine, quetiapine, risperidone, aripiprazole, haloperidol and a combination of olanzapine with escitalopram, diazepam and haloperidol, we studied the effect of these drugs on pancreatic beta cells thereby determining blood glucose, insulin, insulin resistance, $\%$ $\beta$ cells function and c-peptide levels in addition to body weight. Certain authors have reported insulin resistance and impaired beta cells function in patients receiving antipsychotic drug (Houseknecht et al., 2006). It has been reported in a two weeks study that olanzapine significantly decreased insulin level in AAPDs-naïve patients subjected to intravenous glucose tolerance test. Beta cells impairment has been reported in several animal studies with short term use of olanzapine. It has been postulated that these drugs might be having acute effects in susceptible individuals which may decline over time (Chiu et al., 2010; Chiu et al., 2006). Chiu and his colleagues in a study have reported hyperinsulinemia, insulin resistance and normal glucose level with olanzapine (Chiu et al., 2010). The exact mechanism of AAPDs-induced metabolic abnormalities is still unknown but additive effects of genetic predisposition 

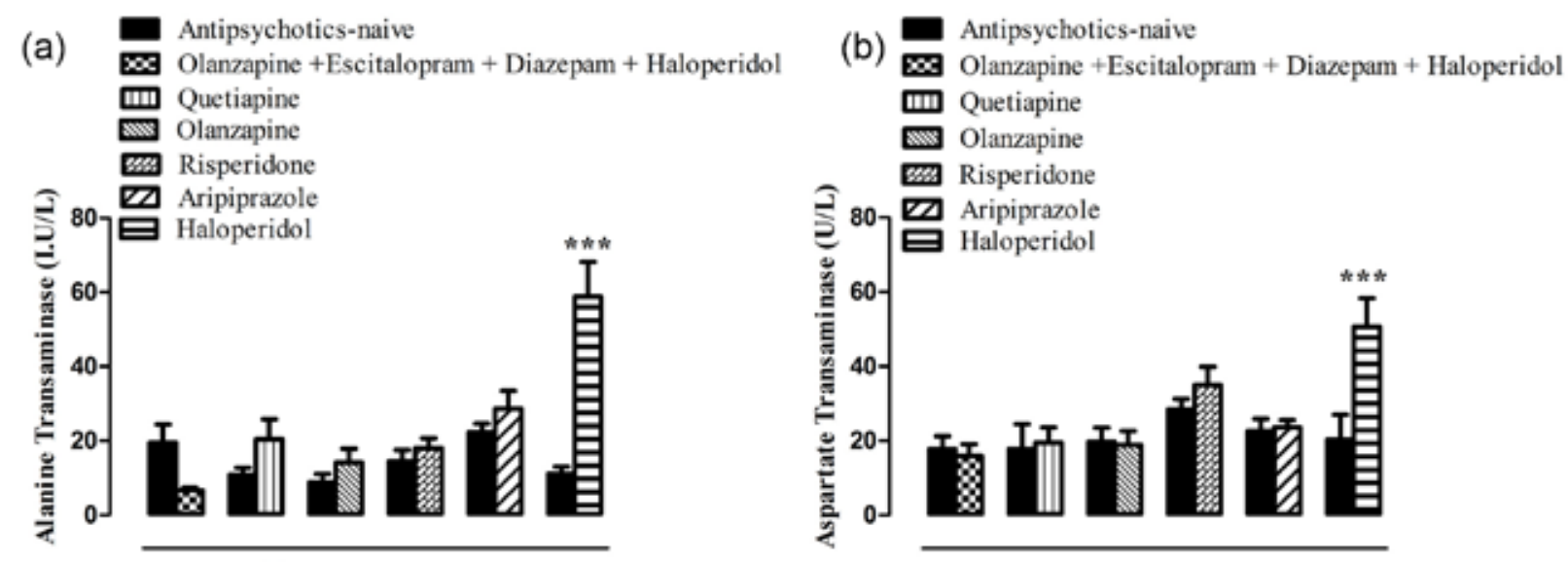

Treatment groups

Treatment groups

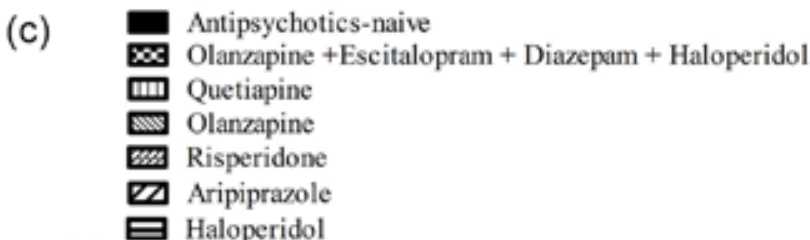
(d) Antipsychotics-naive
$\mathbf{\infty}$ Olanzapine +Escitalopram + Diazepam + Haloperidol

뜨 Quetiapine

Olanzapine

Kisperidone

ש7 Aripiprazole

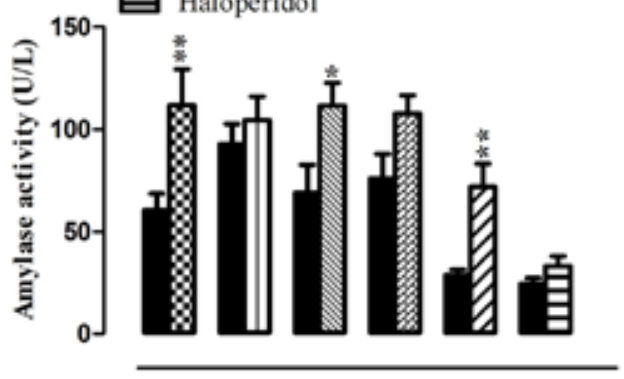

Treatment groups

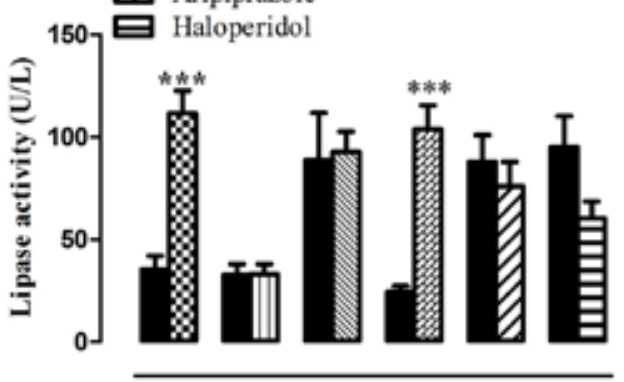

Treatment groups

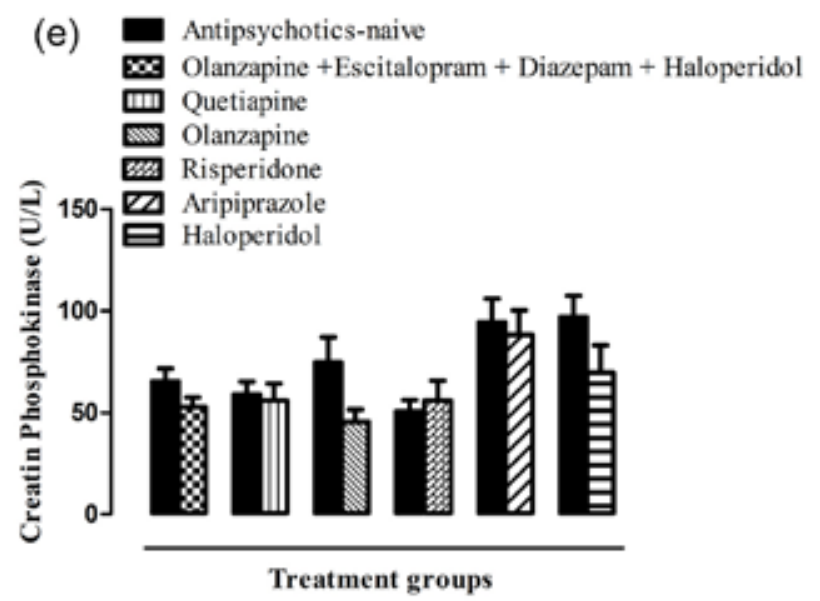

FIGURE 9 - Effect of selected antipsychotics on enzymes: Antipsychotic-naïve patients were treated with olanzapine in combination with escitalopram, diazepam (STAT, I.V) and haloperidol (STAT, I.M) (OLEDH, n=8), or quetiapine (QUET, n=8), olanzapine (OLAN, $n=8)$, risperidone (RISP, $n=8)$, aripiprazole $(n=8)$ or haloperidol $(n=8)$ in therapeutic doses for an average time period of 39, 40, 45, 38, 30 and 33 days respectively showing significant elevation in ALT (a) and AST (b) in haloperidol treated groups as compared to antipsychotics-naive, significant elevation in amylase (c) of combination group $(* * \mathrm{P}<0.01)$, olanzapine $(* \mathrm{P}<0.05)$ and aripiprazole treated groups $(* * \mathrm{P}<0.01)$ as compared to antipsychotics-naïve patients. Significant elevation was observed in lipase $(\mathrm{d})$ of combination group $(* * * \mathrm{P}<0.001)$ and risperidone treated group $(* * * \mathrm{P}<0.01)$ as compared to antipsychotics-naïve patients. No significant change in CPK (e) as compared to antipsychotics-naïve patients was noticed (P $>0.05)($ ANOVA followed by Bonferroni’s Multiple Comparison Test). 

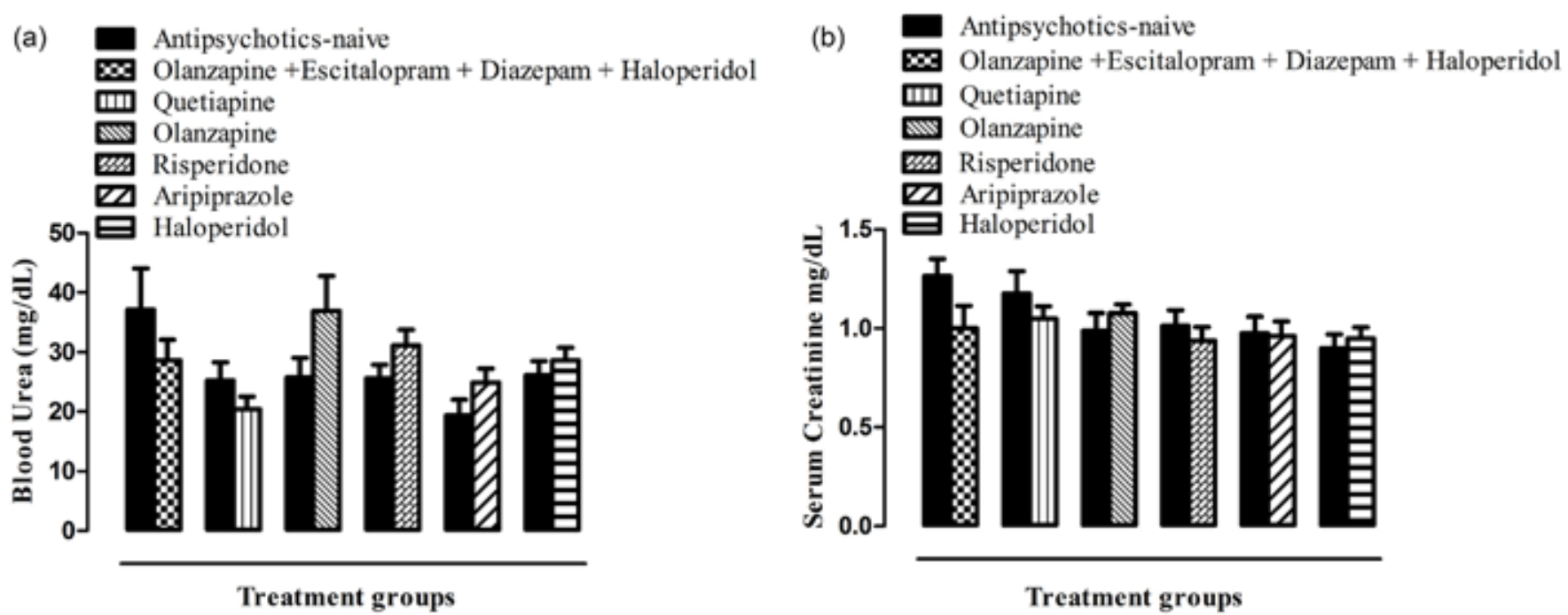

FIGURE 10 - Effect of selected antipsychotics on blood urea (a) and serum creatinine (b): Antipsychotic-naïve patients were treated with olanzapine in combination with escitalopram, diazepam (STAT, I.V) and haloperidol (STAT, I.M) (OLEDH, $\mathrm{n}=8$ ), or quetiapine (QUET, $n=8$ ), olanzapine (OLAN, $n=8)$, risperidone (RISP, $n=8)$, aripiprazole $(n=8)$ or haloperidol $(n=8)$ in therapeutic doses for an average time period of 39, 40, 45, 38, 30 and 33 days respectively showing no significant change in blood urea and serum creatinine as compared to antipsychotics-naïve patients $(* \mathrm{P}<0.05)$ (ANOVA followed by Bonferroni's Multiple Comparison Test).

to pancreatic dysfunction, primary damage to pancreatic beta cells, insulin resistance secondary to weight gain and excessive hunger in patients receiving AAPDs have been nominated (Ballon et al., 2014; Baptista, Parada, Hernandez, 1987; Chiu et al., 2010; Reaven, 2009). In contrast to various studies (Arjona et al., 2004; Baptista, Parada, Hernadez, 1987; Bergman, Ader, 2005), no statistical significance was observed in weight gain with any of the selected drugs in our study. The relationship between insulin, $\%$ beta function, insulin resistance (IR) and c-peptide is quite complex; however, the results of this study showed no significant change in insulin and c-peptide levels which does not support the hypothesis that AAPDs cause pancreatic beta cells damage (Kjems et al., 2000; Sowell et al., 2002). Studies have linked diabetes to a direct drug insult to beta cells of the pancreas invoked by antipsychotic drugs, although weight gain is not the prerequisite of diabetes rather weigh loss could precede the diagnosis of diabetes (Sowell et al., 2002). In a short study of maximum of 17 days exposure to antipsychotics, Sowell and his colleagues are of the opinion that exposure to antipsychotics does not increase or decrease the level of insulin, which is also supported by our study even in the longer drug exposure with a maximum of 45 days (Sowell et al., 2002).

These drugs are being reported to be associated with metabolic syndrome including dyslipidemias, hyperglycemias, obesity, hyperinsulinemia and insulin resistance (Chiu et al., 2010). Previous studies have shown elevated glucose concentrations together with hyperinsulinemia purported to be due to antipsychotic drugs (Chiu et al., 2006; Gohlke et al., 2012; Gomez et al., 2000).

Olanzapine-induced pancreatic damage has also been reported by our laboratory in a chronic study in rats (Shah et al., 2015) and by several other studies (Chiu et al., 2010; Doucette, Grenier, Robertson, 2000; Koller et al., 2003). In addition to above reports, we showed in our study that psychosis by itself, smoking tobacco, charas, cannabis and/or use of oral snuff might be other culprits that predispose the patients to disturbance in insulin and glucose levels.

Owing to the facts described above, we add the following predisposing factors that could disturb glucose homeostasis in patients with psychosis; (1): Psychosis by itself (2): Antipsychotic drugs (3): Use of narcotics (4): Smoking habits (5): Oral snuff (naswar). Dramatically, antipsychotic drugs may sometime be correcting insulin and blood glucose levels, as observed in our patients individually. This dramatic effect of antipsychotics may lead to the conclusion that the unkown behavioral regulating pathways might be linked somewhere to the glucose/lipids regulating/metabolizing pathways. Similarly, based on the above results, it could be hypothesized that the results of antipsychotics in normal individuals with correct behavioral pathways might be different in patients with abnormal behavior (Sowell et al., 2002). The animals used in such studies might be showing inconsistent results due to the fact described above. The inconsistent results have already been reported by our 
laboratory and certain other studies (Baptista, Parada, Hernandez, 1987; Shah et al., 2015; Weston-Green, Huang, Deng, 2013).

There are reports that APDs cause elevation in triglycerides and cholesterol (Lindenmayer et al., 2003; McIntyre et al., 2001). There are also reports of pancreatitis purported to be associated with APDs (Waage, Carlsson, Nielsen, 2004). The exact mechanism remains unclear, but metabolic dysregulation has been nominated especially elevation in triglycrides which in turn causes hyperamylasemia and hyperlipasemia (Lattanzi et al., 2009). In the current study the effects of different antipsychotic drugs on cholesterol and triglycerides were studied, and concluded that aripiprazole causes elevation in cholesterol, whereas none of the other drugs showed any alteration in triglycerides and cholesterol. However, hyperamylasemia was noticed in combination group, olanzapine and aripiprazole treated groups, that alarm disturbance in glucose and insulin in prolonged exposure. Similarly, hyperlipasemia was resulted in combination and risperidone groups giving possible risk of disturbance in lipids if exposed chronically. Studies have reported asymptomatic elevation in ALT and AST (Ozcanli et al., 2006) which is in line with our study showing elevation in the level of ALT and AST with haloperidol only.

Our laboratory and other studies have reported the effects of olanzapine and risperidone on the architecture of kidneys of rats and it was found that high dose of olanzapine $(2.5 \mathrm{mg} / \mathrm{kg}$, i.p) and risperidone $(1 \mathrm{mg} / \mathrm{kg}$, i.p) and low dose of risperidone $(0.5 \mathrm{mg} / \mathrm{kg}$, i.p $)$ are associated with nephrotoxic effects, including irregularities in tubular and glomerular structure, focal necrosis in some areas of renal cortex and medulla, cells with pyknotic nuclei and eosinophilic cytoplasm etc were noticed, but the studies were not supplicated with renal function tests. Our study in human, did not show any elevation in serum creatinine and blood urea.

Further studies on larger population are required with major focus on the biochemistry of drug-naïve schizophrenics, and use of narcotics, smoking and oral snuff in patients with psychosis. Exposure of diabetic subjects to antipsychotics will help in concluding whether these drugs correct or worsen the insulin and glucose levels.

\section{CONCLUSION}

It is concluded that short term use of APDs is not associated with acute alarming events in Pakistani population of Pakhtuns territory. It is concluded that psychiatric disorders by itself, narcotics, cigarette smoking and use of oral snuff may be also be implicated in metabolic dysregulations. The effects of APDs on insulin and glucose in healthy volunteers might be different than in patients with psychiatric disorders.

\section{LIMITATIONS}

Antipsychotic drugs are used lifelong; however, we followed for a short period of 30 to 45 days. Multiple readings of insulin and glucose would better help in concluding APDs-induced toxicity.

\section{ACKNOWLEDGMENT}

We are highly indebted to the Higher Education Commission (HEC), Pakistan for providing partial financial support in this study. We also appreciate the sincere efforts of Mr. Javed Khan, Senior Analyst in RIA laboratory IRNUM, Peshawar and are also grateful to all medical and paramedical staff of the Psychiatry Unit, Khyber Teaching Hospital, Peshawar.

\section{REFERENCES}

Arjona AA, Zhang SX, Adamson B, Wurtman RJ. An animal model of antipsychotic-induced weight gain. Behav Brain Res. 2004;152(1):121-127.

Ballon JS, Pajvani U, Freyberg Z, Leibel RL, Lieberman JA. Molecular pathophysiology of metabolic effects of antipsychotic medications. Trends Endocrinol. Metab. 2014;25(11):593-600.

Baptista T, Parada M, Hernandez L. Long term administration of some antipsychotic drugs increases body weight and feeding in rats. Are D2 dopamine receptors involved? Pharmacol Biochem Behav. 1987;27(3):399-405.

Bergman RN, Ader M. Atypical antipsychotics and glucose homeostasis. J Clin Psychiatry. 2005;66(4):504-514.

Chiu C-C, Chen C-H, Chen B-Y, YuS-H, LuM-L. The timedependent change of insulin secretion in schizophrenic patients treated with olanzapine. Prog Neuropsychopharmacol Biol Psychiatry. 2010;34(6):866-870.

Chiu C-C, Chen K-P, Liu H-C, Lu M-L. The early effect of olanzapine and risperidone on insulin secretion in atypicalnaive schizophrenic patients. J Clin Psychopharmacol. 2006;26(5):504-507. 
Cope M, Nagy T, Fernandez J, Geary N, Casey D, Allison D. Antipsychotic drug-induced weight gain: development of an animal model. Int J Obes. (Lond). 2005;29(6):607-614.

De Hert M, Detraux J, van Winkel R, Yu W, Correll CU. Metabolic and cardiovascular adverse effects associated with antipsychotic drugs. Nat Rev Endocrinol. 2012;8(2):114-126.

Doucette DE, Grenier JS, Robertson PS. Olanzapine-induced acute pancreatitis. Ann Pharmacother. 2000;34(10):1128-1131.

Ebenbichler CF, Laimer M, Eder U, Mangweth B, Weiss E, Hofer A, et al. Olanzapine induces insulin resistance: results from a prospective study. J Clin Psychiatry. 2003;64(12):14361439.

Garcia-Unzueta MT, Herran A, Sierra-Biddle D, Amado JA, Vázquez-Barquero JL, Álvarez C. Alterations of liver function test in patients treated with antipsychotics. J Clin Lab Anal. 2003;17(6):216-218.

Gohlke JM, Dhurandhar EJ, Correll CU, Morrato EH, Newcomer JW, Remington G, et al. Recent advances in understanding and mitigating adipogenic and metabolic effects of antipsychotic drugs. Front Psychiatry. 2012;3:62.

Goldstein LE. New-onset diabetes mellitus and diabetic ketoacidosis associated with olanzapine treatment. Psychosomatics. 1999;40(5):438-443.

Gomez JC, Sacristan JA, Hernandez J, Breier A, Carrasco PR, Saiz CA, et al. Results of an observational prospective study in patients with schizophrenia (EFESO Study). J Clin Psychiatry. 2000;61(5):335-343.

Houseknecht KL, Robertson AS, Zavadoski W, Gibbs EM, Johnson DE, Rollema H. Acute effects of atypical antipsychotics on whole-body insulin resistance in rats: implications for adverse metabolic effects. Neuropsychopharmacology. 2006;32(2):289-297.

Kjems LL, Christiansen E, Vølund A, Bergman RN, Madsbad $\mathrm{S}$. Validation of methods for measurement of insulin secretion in humans in vivo. Diabetes. 2000;49(4):580-588.

Koller EA, Cross JT, Doraiswamy PM, Malozowski SN. Pancreatitis associated with atypical antipsychotics: from the Food and Drug Administration's MedWatch surveillance system and published reports. Pharmacotherapy. 2003;23(9):1123-1130.
Lattanzi L, Casamassima F, Brunetto M, Tatulli A, Longobardi A, Schiavi E, et al. Asymptomatic hyperamylasemia and hyperlipasemia associated with aripiprazole. J Clin Psychopharmacol. 2009;29(5):504-506.

Lindenmayer J-P, Czobor P, Volavka J, Citrome L, Sheitman B, McEvoy JP, et al. Changes in glucose and cholesterol levels in patients with schizophrenia treated with typical or atypical antipsychotics. Am J Psychiatry. 2003;160(2):290-296.

Manu P, Correll CU, Wampers M, van Winkel R, Yu W, Shiffeldrim D, et al. Insulin secretion in patients receiving clozapine, olanzapine, quetiapine and risperidone. Schizophr Res. 2013;143(2-3):358-362.

Matthews D, Hosker J, Rudenski A, Naylor B, Treacher D, Turner R. Homeostasis model assessment: insulin resistance and $\beta$-cell function from fasting plasma glucose and insulin concentrations in man. Diabetologia. 1985;28(7):412-419.

McIntyre RS, McCann SM, Kennedy SH. Antipsychotic metabolic effects: weight gain, diabetes mellitus, and lipid abnormalities. Can J Psychiatry. 2001;46(3):273-281.

McManus DQ. Quetiapine, a novel antipsychotic: experience in elderly patients with psychotic disorders. J Clin Psychiatry. 1999;60(5):292-298.

Meier JJ, Hücking K, Holst JJ, Deacon CF, Schmiegel WH, Nauck MA. Reduced insulinotropic effect of gastric inhibitory polypeptide in first-degree relatives of patients with type 2 diabetes. Diabetes. 2001;50(11):2497-2504.

Mitchell AJ, Lord O. Review: Do deficits in cardiac care influence high mortality rates in schizophrenia? A systematic review and pooled analysis. J Psychopharmacol. 2010;24(4 Suppl):69-80.

Newcomer JW, Haupt DW, Fucetola R, Melson AK, Schweiger JA, Cooper BP, et al. Abnormalities in glucose regulation during antipsychotic treatment of schizophrenia. Arch Gen Psychiatry. 2002;59(4):337-345.

Ozcanli T, Erdogan A, Ozdemir S, Onen B, Ozmen M, Doksat $K$, et al. Severe liver enzyme elevations after three years of olanzapine treatment: a case report and review of olanzapine associated hepatotoxicity. Prog Neuropsychopharmacol Biol Psychiatry. 2006;30(6):1163-1166. 
Pantelis C, Velakoulis D, McGorry PD, Wood SJ, Suckling J, Phillips LJ, et al. Neuroanatomical abnormalities before and after onset of psychosis: a cross-sectional and longitudinal MRI comparison. Lancet. 2003;361(9354):281-288.

Reaven GM. Insulin secretory function in type 2 diabetes: Does it matter how you measure it? J Diabetes. 2009;1(3):142-150.

Shah R, Subhan F, Ali G, Ullah I, Ullah S, Shahid M, et al. Olanzapine induced biochemical and histopathological changes after its chronic administration in rats. Saudi Pharm J. 2015;24(6):698-704.

Sowell MO, Mukhopadhyay N, Cavazzoni P, Shankar S, Steinberg HO, Breier A, et al. Hyperglycemic clamp assessment of insulin secretory responses in normal subjects treated with olanzapine, risperidone, or placebo. J Clin Endocrinol Metabol. 2002;87(6):2918-2923.
Strawn JR, Keck Jr M, Paul E, Caroff SN. Neuroleptic malignant syndrome. Am J Psychiatry. 2007;164(6):870-876.

Vancampfort D, Wampers M, Mitchell AJ, Correll CU, Herdt A, Probst M, et al. A meta-analysis of cardio-metabolic abnormalities in drug naïve, first-episode and multi-episode patients with schizophrenia versus general population controls. World Psychiatry. 2013;12(3):240-250.

Waage C, Carlsson H, Nielsen EW. Olanzapine-induced pancreatitis: a case report. JOP. 2004;5(5):388-391.

Weston-Green K, Huang X-F, Deng C. Olanzapine treatment and metabolic dysfunction: a dose response study in female Sprague Dawley rats. Behav Brain Res. 2011;217(2):337-346.

Weston-Green K, Huang X-F, Deng C. Second generation antipsychotic-induced type 2 diabetes: a role for the muscarinic M3 receptor. CNS Drugs. 2013;27(12):1069-1080.

Received for publication on $21^{\text {st }}$ December 2017 Accepted for publication on $28^{\text {th }}$ May 2018 